\title{
Aerated Concrete Microwave Reflection and Transmission Properties in a Wet Environment
}

\author{
Tarmo Koppel ${ }^{1}$, Inese Vilcane ${ }^{2}$, Viktor Mironov ${ }^{2}$, Andrei Shiskin ${ }^{2}$, \\ Sanita Rubene ${ }^{2}$, Piia Tint ${ }^{1}$ \\ ${ }^{1}$ Department of Work Environment and Safety, Tallinn University of Technology, Ehitajate tee 5, \\ 19086 Tallinn, Estonia \\ ${ }^{2}$ Riga Technical University, \\ Send correspondence to tarmo.koppel@ttu.ee
}

\begin{abstract}
Excess water content within the building material could greatly alter the interaction of the microwave with the material. In this study aerated concrete $(A E R O C)$ block walls $(60 x 60 \mathrm{~cm})$ were investigated for their microwave $(2.4$ $\mathrm{GHz}$ ) properties under wetting conditions. The spray wetting of the wall was conducted to simulate the environmental processes such as raining or water damage. $50 \mathrm{ml} / \mathrm{m}^{2}$ water dosage was applied on the surface of the concrete 21 times in 1 min intervals. The results show a noticeable decrease in microwave penetration power through the material after the sample gets enriched with water. As the water content on the surface of the material rises, so does the transmission loss. During the different water content of the aerated concrete, the reflection loss varied from $-15.04 \mathrm{~dB}$ (dry wall) to $-5.03 \mathrm{~dB}$ (wet wall's surface). The transmission loss continues to rise during the entire length of the experiment, from $-4.5 \mathrm{~dB}$ as a dry sample to $-8.3 \mathrm{~dB}$ after $441 \mathrm{ml}\left(1035 \mathrm{ml} / \mathrm{m}^{2}\right.$ during $\left.23 \mathrm{~min}\right)$ of sprayed water. The variation of reflected microwave power was approximately ten times, which is quite a significant indicator of alteration of microwave propagation. The results demonstrate wetting process as an considerable factor in assessing microwave propagation in near the sources, such as mobile phone base station antennas, industrial microwave heaters and ovens etc.
\end{abstract}

Keywords: electromagnetic fields, microwaves, reflection, transmission, aerated concrete, water, wetting.

\section{INTRODUCTION}

Microwaves attenuate inside the buildings and building materials. Microwave permeability of the construction materials varies to a large degree. A portion of the microwaves is also absorbed and reflected by the materials. Microwave transparent materials include wood, drywall and other lightweight dielectric materials. Reflections within the construction materials or from neighboring surfaces can also account for attenuation of the microwaves as waves may cancel each other out.

Excess water content within the building material could greatly alter the interaction of the microwave with the material. Both reflective and absorptive properties of the materials could be emphasized, resulting in a new electromagnetic wave scenario in the vicinity of the building material. Such cases may become relevant where high power mobile communications or broadcasting antennas are located. While assessing the safety of workers and other people nearby these antennas, the risk assessment is likely to be carried out under conditions without water interaction with the material. In unforeseen cases, where water would affect the reflection properties of the walls surrounding the high power transmission antenna, the microwave exposure levels may be significantly elevated and endanger the nearby people. In such examples, the risk assessment should be always carried out under worst case scenario examples, including the reflective properties of the materials surrounding the antenna.

Water related changes within the material would not only affect the behavior of the electromagnetic fields. Such water related processes could occur and subject building materials to physical reconditioning, likely altering the thermal isolative, structural strength and other properties of the materials. In extreme cases such water damage could even endanger the physical integrity of the building.

In planning shielding characteristics against microwaves, specific construction materials are accounted for their attenuation or transmission effect. Nowadays, a variety of building materials exist with either high transmission or reflection characteristics. Dependent on the chemical composition and the structure of the material, this may greatly affect the microwave propagation. In the literature, almost no attention is paid on the change in the microwave characteristics of the materials under various weather conditions. Cold and rain or the combination of two 
could significantly affect the microwave transmission and reflection properties of construction materials. In this study the focus is on aerated concrete blocks - a popular contemporary building material.

In observing microwave propagation and interaction with materials, three types of behavior can be observed: transmission, reflection and absorption. Microwave transparent materials have low dielectric loss and microwaves pass through it with little or no attenuation. Microwaves reflect back from opaque materials and no transmission occurs. In case of absorbing materials, high dielectric loss causes absorption within the material, and the level of absorption is dependent on the dielectric loss factor. Absorption is in relation with transmission and reflection, where both are reduced and the microwave energy is absorbed within the material and turned into heat [1-4].

The conductive surfaces cause the reflection, where the microwave is reflected from the surface and/or from the inside layers of the material. The capacitive and conductive components of the dielectric response of the material is determined by the dielectric constant and the dielectric loss factor [2].

Determining concrete moisture content (w/c ratio) by means of radar has been undertaken by Sbartai et al., where testing showed that an increase in the degree of water saturation lead to significant decrease in the amplitude of direct and reflected wave, determined by a good correlation. Sbartai et al. concluded it to be directly related to the increase of complex permittivity related to the polarization and conduction mechanisms occurring in the concrete [5].

Also Laurens et al. reported the concrete relative humidity to greatly affect the direct wave signal amplitude of the radar measurements. The frequency of the radar they used was of $1.5 \mathrm{GHz}$, complemented by moisture sensors [6].

Dielectric constant of concrete varies in between 5 to 12 , depending mainly on the moisture content and signal frequency [7]. The variation of water volume in the concrete pores results in great change in the complex permittivity and therefore in the attenuation of the propagation velocity of microwaves from radar [8]. The loss factor is greatly dependent on the concrete moisture state (0-2 for dry concrete; $14-16$ for saturated concrete) [9-11].

\section{METHOD}

In this study aerated concrete (AEROC) block walls were investigated for their microwave properties under wetting conditions. The selected microwave frequency was $2.4 \mathrm{GHz}$, which is a widely used frequency for mobile communications and networking, but also for home microwave cooking or industrial microwave heating. Considering the frequencies of the civilian mobile communications, $2.4 \mathrm{GHz}$ lies approximately at the center of the microwave spectrum utilized for the that purpose. 2.4 $\mathrm{GHz}$ is also the frequency of the microwave oven, since it has good absorption characteristics within the water content in the food.

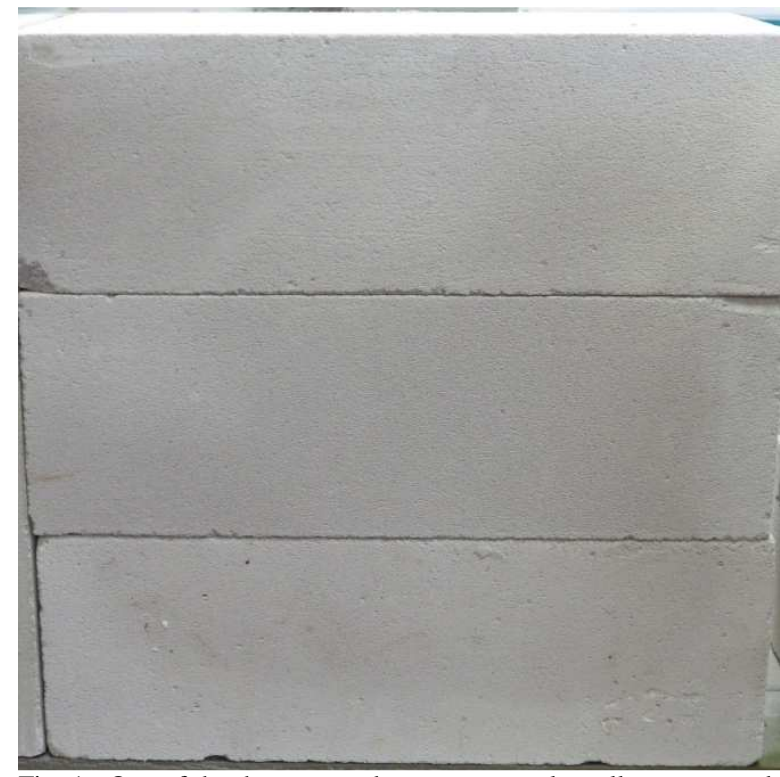

Fig. 1. One of the three aerated concrete sample walls constructed of three blocks.

Three sample walls of the same type of aerated concrete blocks were investigated. The sample surface size was $60 \times 60 \mathrm{~cm}$. Single blocks were of size $60 \times 30 \times 20 \mathrm{~cm}$. For each sample wall, three blocks were piled on top of each other, without the use of blending material (figure 1). Careful attention was paid so to avoid any cracks or gaps within the sample wall, from where the microwaves could leak through.

The moisture content of sample aerated concrete blocks was measured by electrical impedance method. The blocks were determined to be dry. The blocks had been indoors for 2 months with the average room temperature of $20^{\circ} \mathrm{C}$ and average relative humidity $(\mathrm{RH}) 35 \%$.

The wetting of the wall was conducted to simulate the environmental processes such as raining or water damage (figures 2, 3). Wetting was conducted by a hand spray. The wall was subjected to repetitive spraying treatments, each of which delivered $21 \mathrm{ml}$ of room temperature tap water evenly on the $0.6 \times 0.6 \mathrm{~m}$ surface of the sample wall i.e. $50 \mathrm{ml} / \mathrm{m}^{2}$. There was total of 21 spraying treatments, with the accumulating dosage of sprayed water $441 \mathrm{ml}$. The spraying treatments were separated by 1 minute period, during which the water was allowed to be absorbed into the material. By such dosing, there was no dripping of the water and the only water lost from the sample was due to normal drying in the room temperature (21 degrees Celsius, RH $36 \%$ ). By the end of the last spraying treatment, the top layers of the block were absorbed with water. The measurements of transmission and reflection properties were done after 
each spraying treatment, i.e. 21 times, plus an initial dry sample measurement.

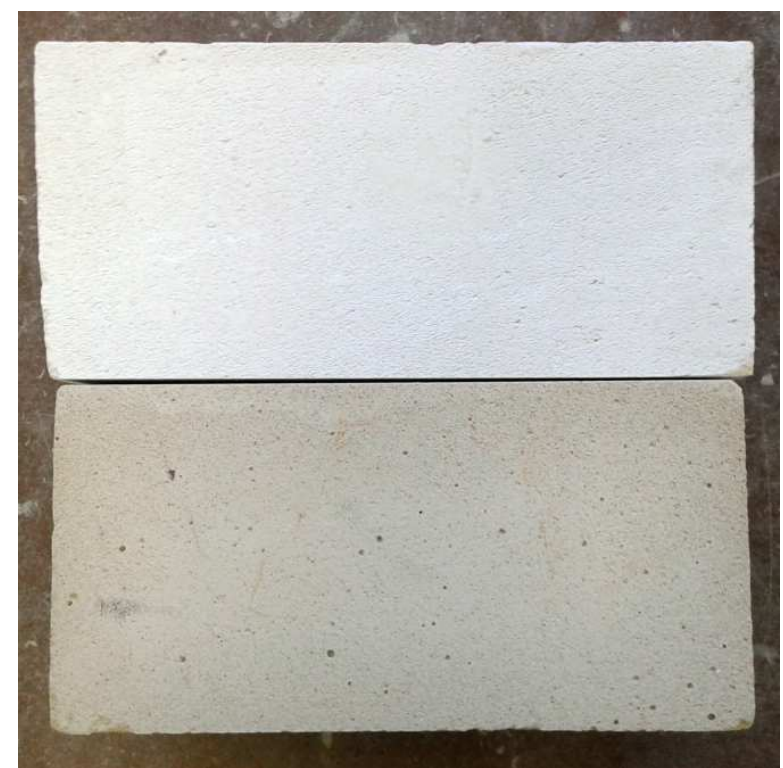

Fig. 2. Aerated concrete sample blocks: above dry and below surface wetted $441 \mathrm{ml}$ during $23 \mathrm{~min}$.

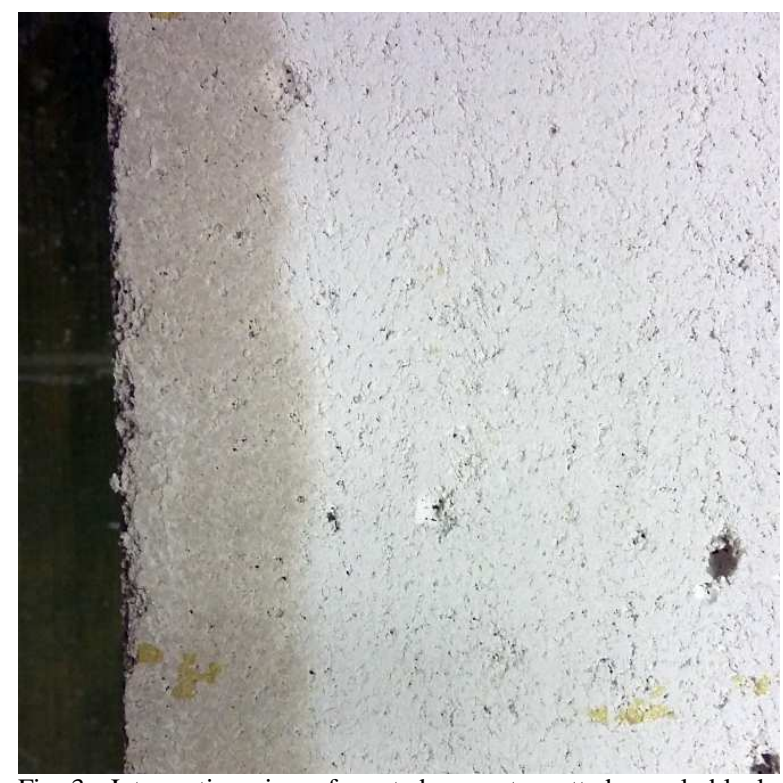

Fig. 3. Intersection view of aerated concrete wetted sample block after dosage of $441 \mathrm{ml}$ sprayed water during $23 \mathrm{~min}-$ the penetration of water into the deeper surface areas is visible up to $\sim 4 \mathrm{~cm}$.

The measurement setup consisted of standard gain horn antennas as presented in figure 4. The antennas were positioned in a manner to place the sample to the far field region (10 wavelengths) while the microwave was hitting the material.

From the transmitting horn antenna, the microwave propagates from the horn antenna in a parallel beam, which is called the near-field or also Fresnel zone. Field divergence takes place in the socalled far-field or Fraunhöfer zone and the wave intensity decreasing by the inverse square law - the amplitude decreases in inverse proportion to distance from the aperture of the horn [22].

The distance of the near field zone (1) in case of rectangular horn opening is to be determined by the formula by Botsco [23] (Formula 1), where A is the dimension of the largest side of the rectangle and $\lambda$ the wavelength. The wavelength of $2.4 \mathrm{GHz}$ electromagnetic field is $0.125 \mathrm{~m}$.

$$
l=\frac{A^{2}}{2 \lambda}
$$

A $2.4 \mathrm{GHz}$ signal generator was used with an output power of $20 \mathrm{dBm}$. The microwave reflecting back from the material and transmitting through the material was measured by a spectrum analyzer Aaronia Spectran HF6080 (Euscheid, Germany), which was controlled and monitored by a PC. In order to register a reflection/transmission incident, ten sequential measurements were monitored, of which the highest reading was automatically recorded.

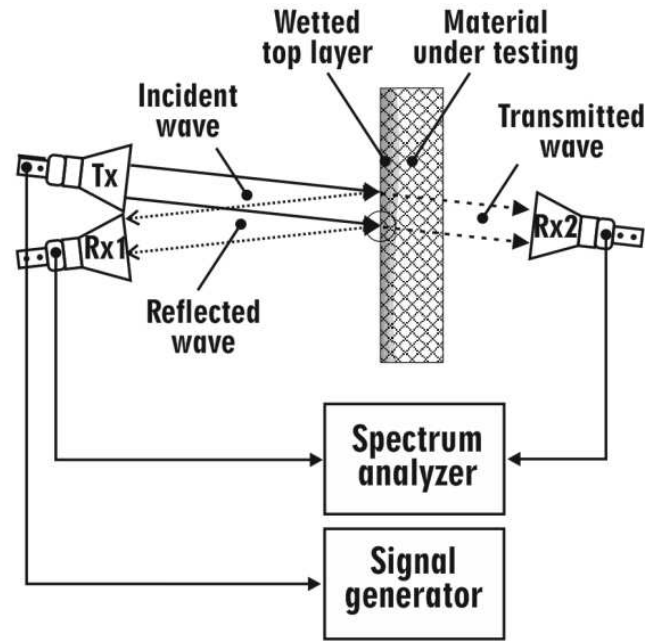

Fig. 4. Measurement setup included irradiator horn antenna Tx and two receiving horn antennas: $\mathrm{Rx} 1$ for reflected wave and $\mathrm{Rx} 2$ for transmitted wave measurement.

Prior and after measuring samples a calibration procedure was done including measuring full and zero reflection/transmission microwave levels. Full reflection was determined by placing a sample size aluminum plate to the sample and measuring full reflection by antenna Rx1, whereas full transmission was determined by leaving the sample tray empty and measuring the fully transmitted wave at antenna $\mathrm{Rx} 2$. Reflection loss $(R L)$ and transmission loss $(T L)$ were calculated to each tested sample as a logarithmic ratio of powers in decibels $(\mathrm{dB})$, as a ratio of the transmitted $\left(\mathrm{P}_{\mathrm{t}}\right)$ or reflected $\left(\mathrm{P}_{\mathrm{r}}\right)$ wave to the full transmission or full reflection $\left(\mathrm{P}_{\mathrm{i}}\right)$. The measurements were registered in unit of measure powers decibel milliwatts $(\mathrm{dBm})$. Ratio in decibels $(\mathrm{dB})$ is a representation of gain or loss of the material under 
testing (MUT). Subtracting two powers $(\mathrm{dBm})$ is resulting in their ratio $(\mathrm{dB})$; reflection loss $(\mathrm{RL})$ in formula 2 and transmission loss (TL) in formula 3.

$$
\begin{aligned}
& R L(\mathrm{~dB})=10 \cdot \log _{10}\left(\frac{P_{r}}{P_{i}}\right) d B=P_{r}\left|d B m-P_{i}\right| d B m \\
& T L(\mathrm{~dB})=10 \cdot \log _{10}\left(\frac{P_{t}}{P_{i}}\right) d B=P_{t}\left|d B m-P_{i}\right| d B m
\end{aligned}
$$

The testing was carried out in a laboratory conditions under the controlled microwave levels. In order to have high reliability of the test results, the reflections were minimized by using specialized forms/materials in the immediate surroundings.

\section{RESULTS}

The results averaged across the samples, show a noticeable decrease in microwave penetration power through the material after the sample gets enriched with water. As the water content on the surface of the material rises, so does the transmission loss. On the other hand, with the rise of the water content, the reflective properties of the material increase as expressed in the decrease of the reflection loss.

The extremities of the transmission and reflection loss were determined by 1) removing the sample and 2) replacing the sample with a fully reflective Aluminum sheet. The maximum transmission loss was registered $-31.8 \mathrm{~dB}$ and the maximum reflection loss $-32.1 \mathrm{~dB}$.

The transmission loss and reflection loss dependency on the amount of accumulated sprayed water is shown on graph 5 .

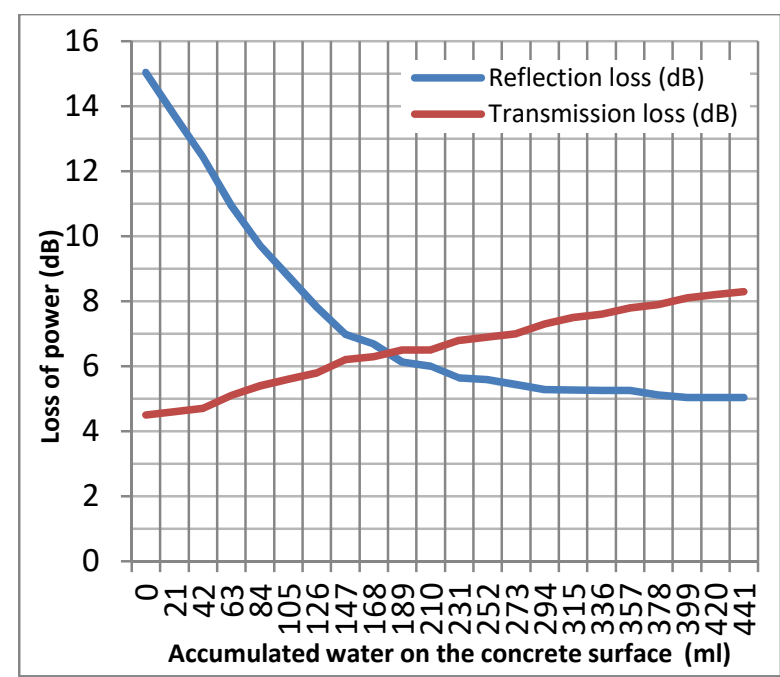

Fig. 5. The transmission loss and reflection loss dependency on the amount of accumulated sprayed water. Vertical bars also constitute of 1 min intervals.

The change in the reflection loss is most evident with the first $210 \mathrm{ml}\left(493 \mathrm{ml} / \mathrm{m}^{2}\right.$ during $\left.12 \mathrm{~min}\right)$ of accumulated sprayed water, after that the reflection loss doesn't change as rapidly. After about $400 \mathrm{ml}$ $\left(937 \mathrm{ml} / \mathrm{m}^{2}\right.$ during $\left.21 \mathrm{~min}\right)$ of sprayed water the reflection loss remains at the same level of approximately $-5 \mathrm{~dB}$. Contrarily, the transmission loss continues to rise during the entire length of the experiment, ending at $-8.3 \mathrm{~dB}$ after $441 \mathrm{ml}$ (1035 $\mathrm{ml} / \mathrm{m}^{2}$ during $23 \mathrm{~min}$ ) of sprayed water.

During the different water content of the aerated concrete, the reflection loss varied from -15.04 dB (dry wall) to $-5.03 \mathrm{~dB}$ (wet wall's surface after 23 min of experiment) which is a variation of $10.01 \mathrm{~dB}$. The results from three samples showed little variability, indicating a good repeatability of the test. The average Delta for the reflection was $0.6 \mathrm{~dB}$ and transmission $0.4 \mathrm{~dB}$ across the corresponding water amount.

\section{CONCLUSIONS AND DISCUSSION}

Although the total reflection (reflection loss of 0 dB) was not achieved, the variation of reflected microwave power was approximately ten times, which is quite a significant indicator of alteration of microwave propagation.

The results demonstrate wetting process as a considerable factor in assessing microwave propagation in near the sources, such as mobile phone base station antennas, industrial microwave heaters and ovens etc. The safety of the people including the workers near such installation and devices should be assessed also accounting for the nearby building materials and their potential being wetted as this may significantly raise the exposure level and put people at risk or inhibit the work of electrical apparatuses.

The results have also pointed out the perspective usage of electromagnetic radiation in assessment of surface water, absorbed into the pours of the concrete. Both registering transmitted and reflected signal has shown a functional dependence on the amount of water absorbed by the concrete sample. Further studies should investigate the attenuation factor dependency on the temperature and humidity conditions in the respective environment, since in a warm and dry environment the natural water evaporation from the concrete surface would be faster and hence the absorbance of water lower.

\section{REFERENCES}

[1] Sutton, W.H., Microwave processing of ceramic materials. Am. Ceram. Soc. Bull. 1989, 68, 376-386.

[2] Thostenson, E.T., Chou, T.-W., Microwave processing: fundamentals and applications. Compos. Part A Appl. Sci. Manuf. 1999, 30, 1055-1071.

[3] Clark, D.E., Folz, D.C., West, J.K., Processing materials with microwave energy. Mater. Sci. Eng. A 2000, 287, 153-158.

[4] Das, S., Mukhopadhyay, A., Datta, S., Basu, D., Prospects of microwave processing: An overview. Bull. Mater. Sci. 2009, $32,1-13$.

[5] Sbartai ZM, Laurens S, Balayssac JP, Ballivy G, Arliguie G. Effect of concrete moisture on radar signal amplitude. ACI materials journal. 2006 Nov 1;103(6):419

[6] Laurens, S.; Balayssac, J.-P.; Rhazi, J.; and Arliguie, G., "Influence of Concrete Moisture Upon Radar Waveform," Materials and Structures, V. 35, No. 248, May 2002, pp. 198203. 
Environment. Technology. Resources, Rezekne, Latvia Proceedings of the $11^{\text {th }}$ International Scientific and Practical Conference. Volume III, 145-149

[7] Bungey, J. H., "Sub-Surface Radar Testing of Concrete: A Review,'Construction and Building Materials, V. 18, 2004, pp. $1-8$

[8] Halabe, U. B.; Bhandarkar, V.; Chen , H.-L.; and Sami, Z. "Detection of Sub-Surface Anomalies in Concrete $\mathrm{Br}$ idge Decks Using Ground Penetrating Radar," ACI Materials Journal, V. 94, No. 5, Sept.-Oct. 1997, pp. 396-408.

[9] Soutsos, M. N.; Bungey, J. H.; Millard, S. G.; Shaw, M. R.; and Patterson, A., "Dielectric Properties of Concrete and their Influence on Radar Testing," NDT\&E International, V. 34, 2001, pp. 419-425.

[10] Rhim, H. C., and Büyüköztürk, O., "Electromagnetic Properties of Concrete at Microwave Frequency Range," ACI Materials Journal, V. 95, No. 3, May-June 1998, pp. 262-271.

[11] Robert, A., "Dielectric Permitti vity of Concrete Between 50 MHZand $1 \mathrm{GHz}$ and GPR Measurements for Building Materials Evaluation," Journal of Applied Geophysics, V. 40, 1998, pp. 89-94 